\title{
LA VIVIENDA RURAL EN GUADALAJARA EN EL SIGLO XVI SEGÚN LAS «RELACIONES TOPOGRÁFICAS DE FELIPE II»
}

\author{
POR \\ ANTONIO LÓPEZ GÓMEZ
}

\section{Introducción}

El extraordinario interés de las Relaciones Topográficas de Felipe II para el conocimiento de la Submeseta Sur en el siglo XVI ha sido subrayado por numerosos autores desde los estudios de Fermín Caballero en el siglo pasado hasta los realizados en nuestros días $(7,8)$. Entre los diversos aspectos de Geografía histórica, uno de gran originalidad, más aun en aquella época, es la vivienda rural, como ya indicó Caballero y también algunos autores en nuestro siglo (Blázquez, Torres Balbás, Jiménez de Gregorio).

En anteriores trabajos ya hemos analizado esta cuestión en las otras provincias modernas de Castilla la Nueva $(9,10,11,12)$, los completamos ahora con la de Guadalajara. Para ésta utilizamos la edición de Catalina García y Pérez Villamil, en el Memorial Histórico de la Real Academia de la Historia (3), sobre la copia de las Relaciones realizada en el siglo xviII por dicha Academia; por tal motivo ha sido tachada de incorrecta por diversos autores, aunque es admitido su valor por Salomon y es suficiente para nuestro objeto.

Como es sabido la pregunta $n .^{\circ} 35$ del interrogatorio de 1575 o la 30 de 1578, se refiere a «la suerte de la casa», los materiales de que

Antonio López Gómez. Inst. de Economía y Geografía (CSIC). Univ. Autónoma. Madrid 
está construida y si proceden del lugar o de fuera; sólo falta la referencia al plano o disposición, muy importante para nosotros. En los demás aspectos permite un conocimiento bastante exacto para aquellos tiempos y de gran utilidad para estudiar la evolución, en muchos casos apenas ninguna hasta casi nuestros días, cuando ya desaparece en muchos sitios la casa tradicional y pronto será únicamente una reliquia en lugares apartados.

Como en trabajos anteriores seguimos un esquema general para toda la provincia, ya que el análisis comarcal sería en exceso prolijo y con numerosas repeticiones y el problema añadido de considerar los espacios percibidos en la época, estudiados en otro lugar (6), o bien los diversos que se estiman hoy; a éstos nos referimos cuando es necesario. Por otra parte, las numerosas relaciones conservadas (un centenar y medio), se refieren en su mayoría a pequeños pueblos de la Alcarria, en segundo lugar a las tierras del Henares ${ }^{1}$, pocas son de las sierras septentrionales y ninguna del extenso resto de la provincia.

En su estudio sobre la casa popular, en 1930, García Mercadal expone que la alcarreña es de dos plantas, con pilares de mampostería en esquinas e intermedios cada tres o cuatro metros; la planta baja se cuaja de cal y canto y la alta, con tosco entramado de maderos, se rellena con tapial de tierra y yeso; no se revoca ni enluce $(4, \mathrm{pp}$. 74-75).

Poco después Torres Balbás ya señala que en las Relaciones Topográficas de Guadalajara, según la edición de Catalina García y Pérez Villamil, "se encuentran noticias interesantes, aunque muy sucintas, de las viviendas de los pueblos alcarreños» e incluye la pregunta correspondiente $(14$, p. 436). Indica que la casa es generalmente «a dos suelos» (bajo y principal), «doblada con cámara» y tejado a dos vertientes; la construcción es como la señalada antes y la viguería, de pino que viene por los ríos de Cuenca o en las casas más pobres de olmo, sauce o roble de la localidad. Comparando con las descritas en las Relaciones, "véese que el caserío alcarreño de hoy es idéntico al de hace cuatro siglos» (14, pp. 434-38 y 496-98).

Lo mismo se puede decir con relación a la Serranía septentrional que estudiamos en otra ocasión (5). Allí, en el macizo antiguo, se emplean bloques de cuarcita o lanchas de pizarra y neis, con barro, en las paredes, la techumbre es de lajas de pizarra o neis; único rasgo 
diferenciador respecto al siglo xVI es, en algunos casos, la cubierta parcial o total de teja, el frecuente enlucido interior tosco y quizás mayor tamaño en ciertos sitios. En los valles periféricos mesozoicos se emplea arenisca o caliza y teja.

En varios lugares se refiere Flores a la casa de Guadalajara, con diversos ejemplos. Señala la construcción de mampostería, mixta o no, con adobe o tapia (Torija, Algora, Palazuelos) y el frecuente entramado: «la Alcarria es también tierra de entramados en gran medida, afines a los del grupo Cuenca-Teruel» (Pastrana, Cogolludo, Atienza), y es mayor el parecido con las serranías Ibéricas que con las Centrales (2, pp. 286-87 y 378); igualmente parece incluir la zona NE en la casa de piedra del Sistema Ibérico (2, pp. 304-6).

Veamos ahora, excluyendo la ciudad de Guadalajara, lo que decían las Relaciones en el siglo xvi y las notorias semejanzas.

\section{Rasgos generales}

Calidad y tamaño.-Hay una treintena de referencias, en su mayoría de carácter peyorativo. Se dice que son casas toscas, pequeñas, comunes, de poco valor, etc., en un quincena de pueblos: Alovera, Atanzón, Cañizar, El Casar, Caspueñas, Escopete, Fuencemillán, La Mierla, Mohernando, Retuerta, Valdeavellano, Valdelaguna, Valdesaz, Valtablado y Villanueva de la Torre (fig. 1). En cuatro son ya ruines o miserables: Lupiana, Sacedoncillo (Sacedón en el texto), Uceda y Viana de Mondéjar; llega a decirse que «casi no se pueden habitar» en Fresno de Málaga (hoy despoblado en Málaga del Fresno). En Sotoca se explica que es debido a la pobreza del lugar: «no son muy buenas porque nosotros somos pobres y no las podemos edificar mejores»; en Alovera por falta de leña «para cocer teja y ladrillo son la mayor parte de las casas muy pequeñas»; en Berniches son de mejor calidad desde hace 50 años.

Son «razonables» en Cogolludo y algunas en Yélamos de Yuso (Abajo); «mejores que de aldea, al uso toledano, aunque no muy costosas» en Almoguera. En Cogolludo, Mohernando y Yunquera destaca la del señor; en Fuentelaencina y Escariche hay algunas casas buenas y se califican de muy buenas en Almonacid de Zorita, Pastrana, Mondéjar y Tendilla; en esta última tienen «aposentos y salas 


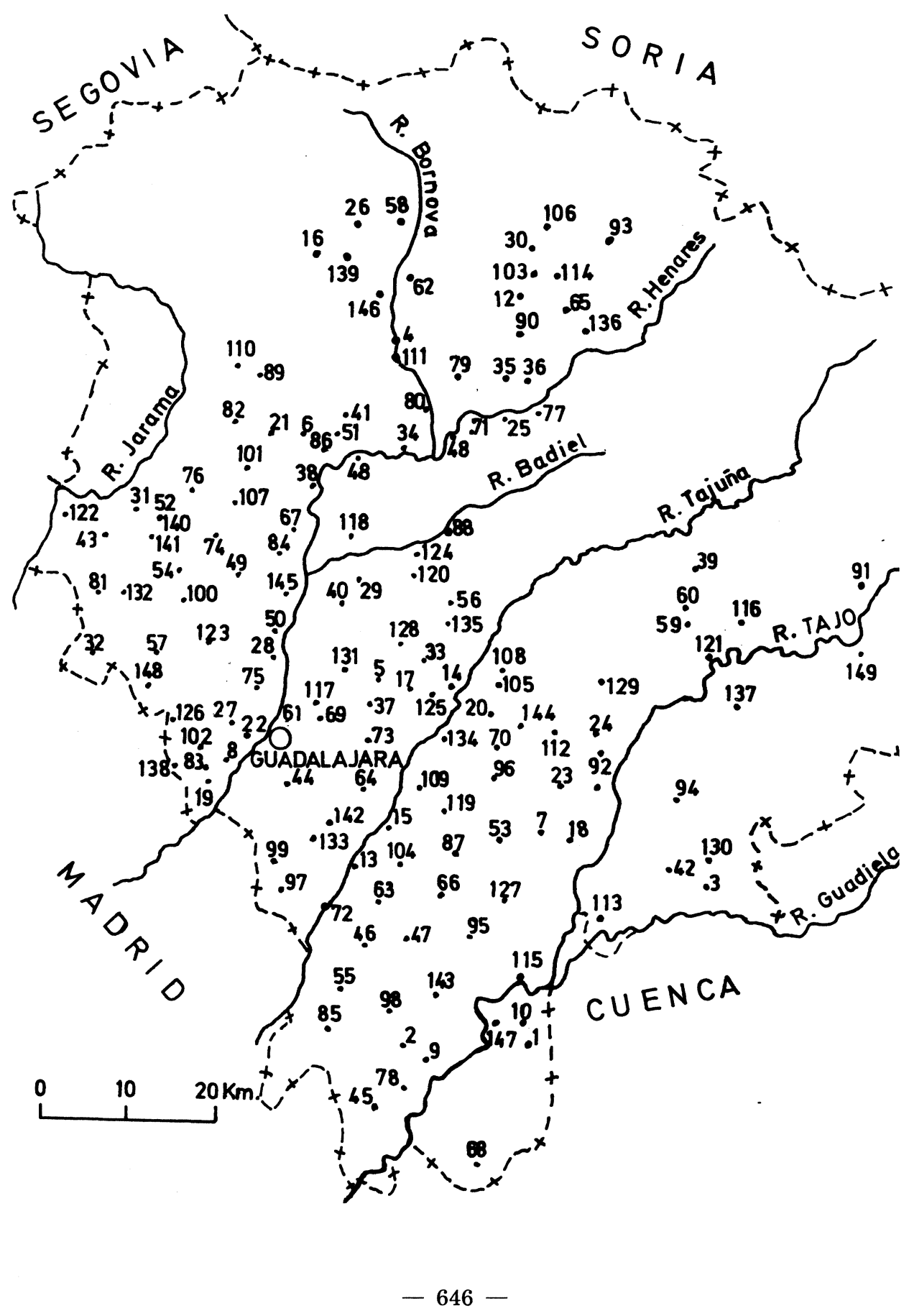




\section{FIgURA 1.-Relaciones (nomenclatura actual)}

\begin{tabular}{|c|c|c|}
\hline 1. Albalate de Zorita. & 50. Fontanar. & 100. Puebla de Guadalajara. \\
\hline 2. Albares. & 51. Fuencemillán. & 101. Puebla de Beleña. \\
\hline 3. Alcocer. & 52. Fuente el Fresno. & 102. Quer. \\
\hline Alcolea de Torote (148). & 53. Fuentelaencina. & 103. Rebollosa de Jadraque. \\
\hline 4. Alcorlo. & 54. Fuentelahiguera. & 104. Renera. \\
\hline 5. Aldeanueva de Guadalajara. & 55. Fuentenovilla. & 105. Retuerta. \\
\hline 6. Aleas. & 56. Fuentes de la Alcarria. & 106. Riofrío. \\
\hline 7. Alhóndiga. & 57. Galápagos. & 107. Robledillo de Mohernando. \\
\hline 8. Alovera. & 58. Gascueña. & 108. Romancos. \\
\hline 9. Almoguera. & 59. Gárgoles de Abajo. & 109. Romanones. \\
\hline 10. Almonacid de Zorita. & 60. Gárgoles de Arriba. & 110. Sacedoncillo. \\
\hline 11. Alocén. & 61. Guadalajara. & 111. San Andrés del Congosto. \\
\hline 12. Angón. & 62. Hiendelaencina. & 112. San Andrés del Rey. \\
\hline 13. Aranzueque. & 63. Hontoba. & 113. Santa María de Poyos. \\
\hline 14. Archilla. & 64. Horche. & 114. Santiuste. \\
\hline 15. Armuña de Tajuña. & 65. Huérmeces. & 115. Sayatón. \\
\hline 16. Arroyo de las Fraguas. & 66. Hueva. & 116. Sotoca. \\
\hline 17. Atanzón. & 67. Humanes. & 117. Taracena. \\
\hline 18. Auñón. & 68. Illana. & 118. Taragudo. \\
\hline 19. Azuqueca. & 69. Iriépal. & 119. Tendilla. \\
\hline 20. Balconete. & 70. Irueste. & 120. Trijueque. \\
\hline 21. Beleña. & 71. Jadraque. & 121. Trillo. \\
\hline 22. Benalaque. & 72. Loranca de Tajuña. & 122. Uceda. \\
\hline 23. Berniches. & 73. Lupiana. & 123. Usanos. \\
\hline 24. Budia. & 74. Malaguilla. & 124. Valdearenas. \\
\hline 25. Bujalaro. & 75. Marchamalo. & 125. Valdeavellano. \\
\hline 26. Bustares. & 76. Matarrubia. & 126. Valdeaveruelo. \\
\hline 27. Cabanillas del Campo. & 77. Matillas. & 127. Valdeconcha. \\
\hline 28. Cañal, El. & 78. Mazuecos. & 128. Valdegrudas. \\
\hline 29. Cañizar. & 79. Medranda. & 129. Valdelagua. \\
\hline 30. Cardeñosa. & 80. Membrillera. & 130. Valdeloso. \\
\hline 31. Casas de Uceda. & 81. Mesones. & 131. Valdenoches. \\
\hline 32. Casar de Talamanca. & 82. Mierla. & 132. Valdenuño Fernández. \\
\hline 33. Caspueñas. & 83. Miralcampo. & 133. Valdarachas. \\
\hline 34. Carrascosa de Henares. & 84. Mohernando. & 134. Valfermoso de Tajuña. \\
\hline 35. Cendejas de Enmedio. & 85. Mondéjar. & 135. Valdesaz. \\
\hline 36. Cendejas de la Torre. & 86. Montarrón. & 136. Viana de Jadraque. \\
\hline 37. Centenera. & 87. Moratilla de los Meleros. & 137. Viana de Mondéjar. \\
\hline 38. Cerezo de Mohernando. & 88. Muduex. & 138. Villanueva de la Torre. \\
\hline 39. Cifuentes. & 89. Muriel. & 139. Villares. \\
\hline 40. Ciruelas. & 90. Negredo. & 140. Villaseca de Uceda. \\
\hline 41. Cogulludo. & 91. Ocentejo. & 141. Viñuelas. \\
\hline 42. Córcoles. & 92. Olivar, El. & 142. Yebes. \\
\hline 43. Cubillo de Uceda, El. & 93. Olmeda, La. & 143. Yebra. \\
\hline 44. Chiloeches. & 94. Pareja. & 144. Yélamos de Abajo. \\
\hline 45. Driebes. & 95. Pastrana. & 145. Yunquera. \\
\hline 46. Escariche. & 96. Peñalver. & 146. Zarzuela de Jadraque. \\
\hline 47. Escopete. & 97. Pioz. & 147. Zorita de los Canes. \\
\hline 48. Espinosa de Henares. & 98. Pozo de Almoguera. & 148. Alcolea de Torote. \\
\hline 49. Fresno de Málaga. & 99. Pozo de Guadalajara, El. & 149. Valtablado del Río. \\
\hline
\end{tabular}




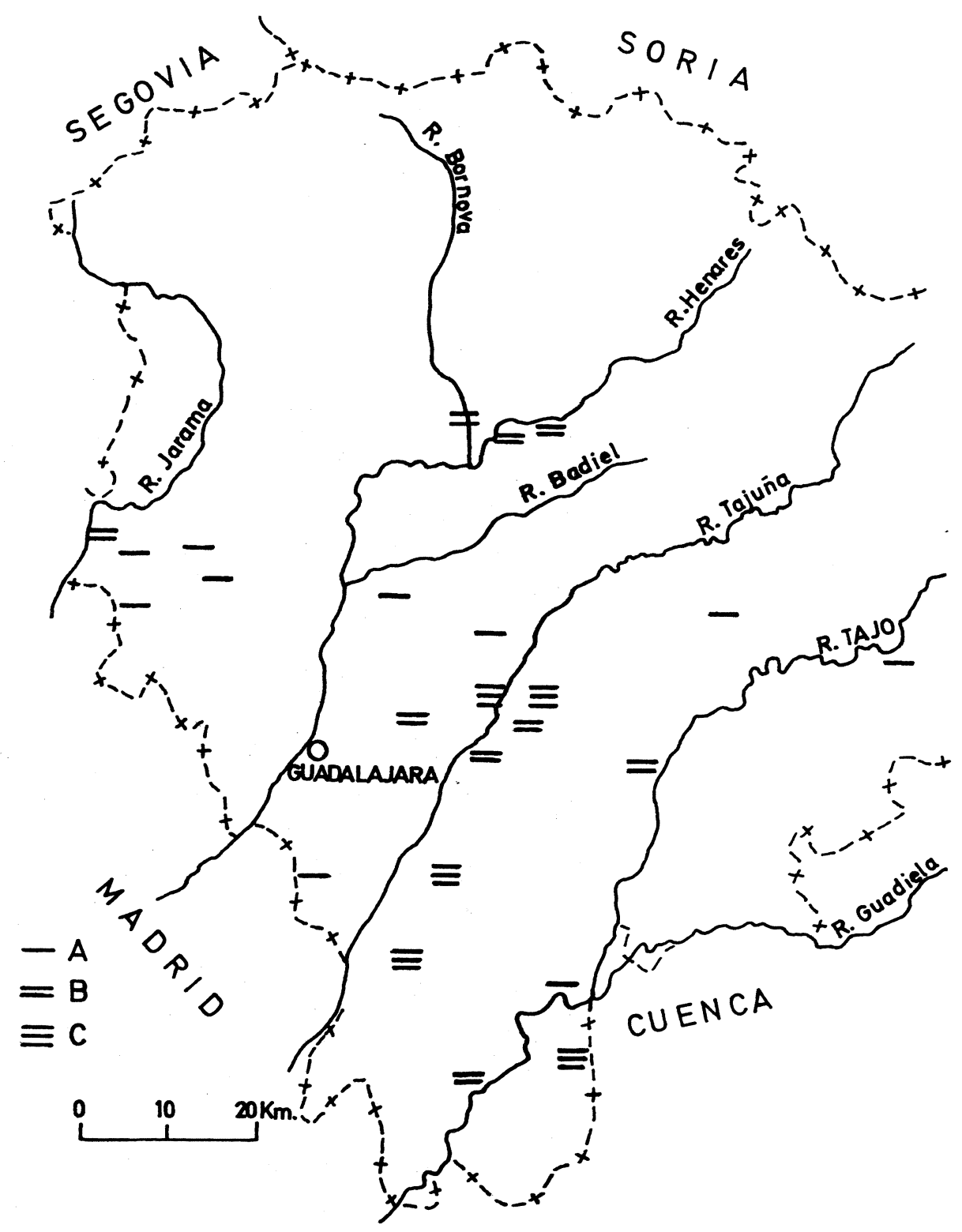

Figura 2.-Número de plantas: A, planta baja; B, cámara, dos suelos; $C$, dos o tres suelos.

$$
-648-
$$


muy preciados con muy buenas portadas y ventanage, de obra romana y curiosas molduras en muy buenas maderas de nogal y pino».

Plano y alzado.-No hay pregunta específica sobre la disposición y, por ello, sólo se encuentran un par de indicaciones. En Pastrana «hay muchas casas con patios», por el contrario, en Renera, a unos $15 \mathrm{~km}$, «las casas son sin patio a usanza de las de la Alcarria de labradores». En Tendilla, con muy buenas casas como se ha dicho, en la plaza y calles hay «saledizos y portales que aunque llueva se puede andar la mayor parte de la villa sin barros»; hoy subsisten allí muchos soportales y es el único núcleo en que se citan.

Solamente en unas dos docenas de sitios se dice que la casa es de una planta o de más, por igual. En varios pueblos, simplemente, se indica que son «llanas» (Sayatón) o «bajas» (Cañizar, Gárgoles de Arriba, Mesones) (fig. 2); se especifica que ello se debe a razones climáticas en Fuentelahiguera y Viñuelas, por ser tierra alta y fría, aunque están en la Campiña del Henares, y en El Pozo de Guadalajara, en la Alcarria, «por la frialdad de la tierra». Se especifica que no tienen más de un suelo en El Cubillo y Valdesaz, en Valtablado son «sin altos ni sobrados algunos».

En Centenera ya se precisa que están «doblados con cámara», en Alhóndiga «algunas de un suelo y otras de dos»; en Almoguera se deduce del texto: «cal y canto hasta los pisos principales», también en Trijueque con «el primer suelo de piedra y barro, y lo demás es un tabique de adobes», en Uceda tapiería «hasta el primer suelo» y luego yeso.

Son de «dos suelos en alto» en Bujalaro, Jadraque, Membrillera, El Olivar (allí se dice que por ello, «sufren más por ser la tierra alta y fría») y Valfermoso. Son de dos a tres suelos en Albalate, Archilla, Escariche, Renera y Retuerta. Todas las menciones corresponden a localidades de la Alcarria y algunas del valle medio del Henares, ninguna a la Campiña, salvo Uceda, ni a la Sierra.

Solamente en dos sitios se mencionan construcciones auxiliares, bodegas en ambos casos. En Tendilla hay «las mejores bodegas para tener vino que se hallan en España..., cavadas en tierra..., parecen casas»; en Sayatón, en la casa del señor, hay «casa cocedero para el vino con su bodega».

Un elemento de la casa puede ser el pozo, pero en la mayoría de los pueblos el agua se obtiene de fuentes. Sólo en una veintena se ci- 
tan pozos, serán colectivos cuando hay uno nada más o varios; se mencionan «muchos» en Cañizar y El Cubillo, en Mondéjar «en las casas hay muchos pozos», pero solamente hay dos referencias individuales: en Almoguera «en todas las casas hay pozos» y en Miralcampo, donde no existe fuente, «beben de pozos que cada vecino tiene hecho en su casa».

Por último, en relación con la distribución interna puede citarse la doble ocupación por dos vecinos. En la mayoría de los pueblos sólo se indica el número de éstos y en una veintena se concreta que es igual el de casas. Sin embargo, en una docena de pueblos, medianos en general, hay más vecinos; la diferencia es 10 a 30 y en Iriépal se explica que «se han dividido casas», solamente en tres sitios la diferencia es mayor: en Yebes 420 vecinos en 370 edificios, en Tendilla 700 y 600 respectivamente, en Pastrana 1.200 y 1.000. Este hecho, no frecuente en el mundo rural, también aparece en las otras provincias y se ha atribuido al aumento de población en la época (13); efectivamente en bastantes sitios se alude a tal crecimiento demográfico.

Por el contrario, en siete pueblos hay menos vecinos que viviendas, en general son pequeños con disminución de habitantes y en algunos se dice que hay casas «vacías» o «vacas» (Medrana, Valtablado); el único de mayor importancia es Trijueque, con 350 vecinos y 360 casas.

\section{Paredes}

La construcción responde esencialmente a los materiales que ofrece el terreno. En el interior de la Serranía Septentrional, en el macizo antiguo, se utilizaría neis, cuarcita y pizarra, como hasta hoy (5), pero sólo aparece una mención de pizarra en Arroyo de las Fraguas; en el borde mesozoico sería arenisca o caliza.

En la Alcarria se emplearía caliza del páramo, también pedernal y toba, pero sólo hay dos citas; en Valdeloso, en el extremo SE, la caliza puede referirse también a la fabricación de cal: «hay piedra para edificar, no de arena sino de pedernal y caleriza, que se puede hacer cal»; en Almoguera, "piedra toviza y pedernales». En el borde de la Campiña, en Aleas, "canto blanco e pardo» (sería de cuarcita de terrazas del Sorbe).

$$
-650-
$$


En muy pocos sitios se refiere la labra; en Uceda se distingue «piedra para sillería mucha y para mampostería también mucho calerizo y gorrón que se dice pelado» (canto rodado); sólo se cita otra vez «mampostería de cal y arena» en Mondéjar; en Escariche «piedra franca y tapias de tierra», pero algunas «de cantería muy bien labradas».

En la Alcarria, sobre cimientos de piedra, se emplea el tapial; éste es material exclusivo en buena parte de la Campiña del Henares. El adobe se emplea en varios pueblos del curso medio y el ladrillo en pocos sitios, en forma de pilares o esquinas. El yeso es de uso muy frecuente y bastante la cal.

En algunos casos se percibe cierta tendencia hacia la mejoría en las construcciones, con mayor empleo de calicanto o de ladrillo, por ejemplo, en Berniches son «algunas de calicanto y la mayor parte e más antiguas de yeso»; en Quer tienen cimientos de piedra y el resto es de tapiería, pero «de algunos años a esta parte en casas que nuevamente se hacen, se echan algunos pilares de ladrillo»; en Romancos son «de tapias y yeso bien fundado e trazadas a lo nuevo que al presente se usan»; en Uceda son de tapiería y yeso, pero «vase reformando a lo nuevo de cal y canto con mejor disposición aunque poco se reforma».

La madera se menciona de manera genérica, en muy pocos lugares se relaciona directamente con las paredes por la cual no sabemos la frecuencia de la casa entramada. No hay citas de puertas y ventanas, que serían pequeñas; en pocas se emplearía vidrio, que no figura nunca. Aunque tampoco la necesaria clavazón, salvo un caso, en Fuentelaencina «alguno se hace allí, la mayor parte de Vitoria o de Vizcaya».

Piedra.-Es material básico en una treintena de pueblos. La mitad de ellos en la Serranía septentrional (fig. 3), salvo una mención de pizarra, se dice simplemente piedra, cantos o guijarros, con barro o «lodo», nunca se indica cal o yeso como mortero. A este tipo corresponde el macizo antiguo, donde sería neis, cuarcita y pizarra: Arroyo de las Fraguas (única cita de ésta), Hiendelaencina (Allendelaencina en el texto), Bustares, Gascueña, Villares y Zarzuela. En el borde mesozoico se emplearía caliza o arenisca: Alcorlo, Angón, Cardeñosa, Rebollosa, Riofrío, Sacedoncillo (Sacedón en el texto), Santiuste, San Andrés del Congosto. 
Las demás citas corresponden a la Alcarria, donde se emplearía la caliza del páramo, también algún caso de pedernal y toba, según se ha dicho; como mortero, cal y yeso que se citan también y alguna vez barro. En este grupo se encuentran Cifuentes, Gárgoles de Abajo y de Arriba, Fuentes, Mondéjar, Ocentejo, Pareja, Peñalver, Retuerta, San Andrés del Rey, Sayatón, Sotoca, Trillo, Valdeconcha, Valdegruda y Valdesaz. Han de añadirse, en la Campiña, Aleas y Fuencemillán.

Tapiería de tierra.-La tierra apisonada se emplea en muchos sitios como material único; en otros, con cimientos de piedra, se estudia después. Se dice que la casas son de «tierra», simplemente, o de «tapiería» o "tapias de tierra»; no se emplea la palabra «tapial», que es la horma o molde en que se apisona la tierra, según figura aun como única acepción en el Diccionario de Autoridades del siglo XVIII, más tarde se aplicaría también a la pared misma.

En algunos sitios se cita a la vez yeso, sin especificar la forma de empleo o como refuerzos o «rafas». La tierra debe proceder del lugar mismo, solamente en El Casar se trae de fuera «porque no es buena».

Como material único se utiliza especialmente en la Campiña del Henares (fig. 3): Casa de Uceda, El Casar (de Talamanca), Cerezo, Fuente el Fresno, Fuentelahiguera, Galápagos, Mesones, Miralcampo, Muriel, Robledillo (de Mohernando), Valdenuño Fernández, Villanueva de Guadalajara, Villaseca de Uceda y Viñuelas. También cerca, en Valdearenas, ya en La Acarria. De acuerdo con la poca consistencia de este material, en ningún sitio, salvo Uceda, se mencionan casas de dos plantas y en varios se concreta que son bajas.

En algunos otros lugares el tapial se refuerza con pilares de ladrillos, como exponemos más adelante.

Piedra y tierra.-Lo más corriente en los numerosos pueblos alcarreños y en el valle medio del Henares es el uso de ambos materiales. En muchos casos simplemente se cita tierra y piedra o cantos, cuando se dice «barro» suponemos que es para unir las piedras, con frecuencia se menciona yeso y también cal. Se indica esta construcción en una veintena de pueblos: Albares, Albalate, Alocén, Carrascosa, Cendejas de Enmedio y de la Torre, Córcoles, Drieves, Escariche, Huérmeces, Loranca, Matillas, Mazuecos, Montarrón, Negredo, El Olivar, Pozo de Almoguera, Renera, Valdelaguna, Valfermoso, Viana de Mondéjar y Yebra. 


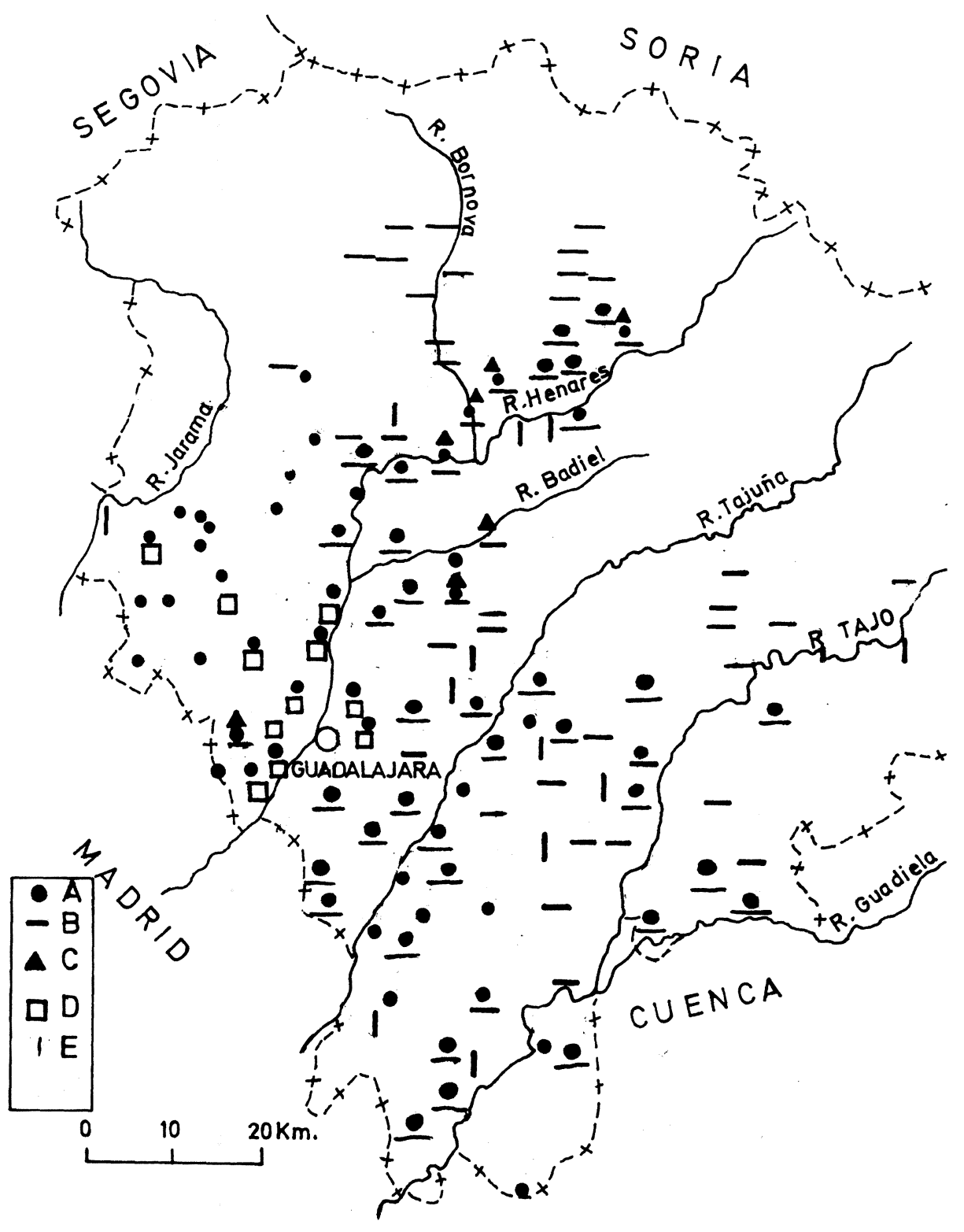

Figura 3.-Materiales de construcción. A, tapias de tierra; $B$, piedra; $C$, adobe; D, ladrillo; $E$, varios tipos.

$-653-$ 
En otros se concreta el uso de la piedra en los cimientos y encima tapiería de tierra: Armuña, Benalaque, Cañizar, Centenera, Ciruelas, Chiloeches, Espinosa, Fuentenovilla, Horche, Humanes, Pioz, Quer, Taragudo, Valderachas, Yélamos de Abajo y Yebes. En Almoguera se especifica que son de calicanto o piedra y barro «hasta los pisos principales... y dende allí arriba de tapia de tierra», en Trijueque es «el cimiento y primer suelo ...de piedra e barro e lo demás es un tabique de adobes e yeso».

Adobe.-En contra de lo que pudiera pensarse, este material, que necesita moldeo y secado previos, se cita poco, igual que en otras provincias de Castilla la Nueva. En la de Guadalajara se menciona en varios pueblos, próximos entre sí, del valle medio del Henares, quizás por un efecto de difusión; a la vez se cita piedra y tapia, por lo cual no cabe confusión con ésta: Carrascosa, Medranda, Membrillera, Vianilla (hoy Viana de Jadraque) y San Andrés del Congosto, donde se explica que «se hacen los dichos adobes de tierra». Más al S, ya en la Alcarria, en Muduex y Trijueque; en el extremo meridional de la Campiña, en Quer.

Ladrillo.-Es material costoso ya que exige arcillas adecuadas, moldeo y cocción. En las llanuras del Duero, como dice Torres Balbás, «el ladrillo, que hoy parece al vulgo un material pobre, lo fue, en las viviendas de Castilla, de relativa riqueza, reservado para palacios y templos» (14, p. 388). En las Relaciones se cita poco en otras comarcas de Castilla la Nueva, salvo en el N de Toledo (11) y el autor antes mencionado llama la atención sobre la carencia en la casa alcarreña «respondiendo sin duda a no haber buenas arcillas para fabricarlo» (14, p. 438), efectivamente, en la Alcarria suelen estar muy cargadas de carbonatos. En cambio, son de mejor calidad en la Campiña del Henares y de esta comarca son casi todas las citas, aunque la fabricación no debía hallarse muy extendida porque casi siempre se dice que «es de fuera». En unos casos se incluye, simplemente, entre los materiales empleados: Azuqueca, Cabanillas, La Puebla de Guadalajara; en otros se concreta el uso en forma de pilares o esquinas en casas de tapiería (en algunas): Alovera, El Cubillo, Fontanar, Quer, Marchamalo, Usanos, Yunquera; también en Iriépal y Taracena, en el inmediato borde alcarreño, y en el extremo S, en Mondéjar.

Yeso.-Abunda mucho en los depósitos miocenos alcarreños, se emplea en la mayoría de los lugares, unos ochenta, y de forma muy 
diversas, por lo cual no se representa en el mapa. En muchos se dice que es del término y en alguno se precisa que es abundante (Berniches, Bujalaro, Jadraque, Yebra); solamente en cuatro se indica que viene de fuera (Trijueque, Taracena, Valdeloso y Yélamos de Yuso o de Abajo).

En la mayoría figura simplemente entre los materiales utilizados y la enumeración sería demasiado prolija. En algunos se concreta el uso, sería como mortero, en pilares o postes de piedra (Mondéjar, Yebes), de ladrillo (Taracena) o de ambos (Iriépal), en otros se cita «piedra, barro y postes de yeso» (Almoguera, Fuentenovilla), o bien tapias y postes de yeso (Horche, Hueva, Irueste). También deben referirse a éstos las citas de Valdeloso, con casas de piedra, barro y "colondos de yeso» ${ }^{2}$, y de Córcoles, donde se usa piedra y tapias de tierra «guarnecidas de colondos de yeso».

En bastantes se menciona a la vez que las tapias de tierra, en forma indeterminada (¿en junturas? ¿en mezcla?) y se dice que las viviendas son de yeso y tierra; salvo Beleña y Puebla de Beleña, campiñesas, todas las demás en la Alcarria: Alcocer, Balconete, Hontova, Illana, Loranca, Lupiana, Romanones, Valdeavellano y Zorita. En pocas se especifica más: "tierra hecha tapias con yeso» en Aranzueque, «tapias y yeso bien fundado» en Romancos, «tapias de tierra labrada con algún yeso» en Villar. En forma de «rafas» o refuerzos se indica en Yeles, también, además de postes, en Hueva, «con sus cintas y rafas» en Fuentenovilla.

En ciertos sitios es el único material que se cita en la mayor parte de las casas: Almonacid, Auñón, Berninches, Cogolludo, Fuentelaencina y Moratilla. Se concreta más en Uceda, con «tapiería hasta el primer suelo y de allí arriba tabiques de yeso», éstos se citan también en Chiloeches, Fuentenovilla, Fuentes, Irueste y Pastrana. En un par de casos se especifica que son los «atajos» (separaciones o divisiones según el Diccionario), en Budia «las cerraduras y atajos de las casas se hacen de yeso», y en Pioz «los atajos de los aposentos». El yeso fraguaría en hormas o moldes de madera, a semejanza de las tapias de tierra apisonada; probablemente se emplearían postes de madera intermedios, puesto que en Fuencemillán y Moratillas las casas

2 «Colonda», según el Diccionario de la Academia (ed. 1970, Supl., p. 1385) es poste o pie derecho, especialmente en tabiques. En la edición de las Relaciones, en Valdeloso se dice en nota: «tabiques». 
son «de madera y yeso», y la mayoría de Tendilla, en Beleña «de tierra e yeso e madera»; ya se especifica en Jadraque que algunas son de calicanto "y otras de pies de madera y tabiques de yeso», y en Puebla de Beleña son de yeso y tapias «armadas de pies de madera».

Unicamente en dos pueblos se indica el uso para revoco o enlucido; en Hueva las viviendas de tierra, con postes y rafas de yeso, están «lucidas en parte con yeso» y en Yebra los edificios, de piedra y tierra, «van revocadas con yeso».

Es interesante señalar que en la Cosmografía de España de Fernando Colón, a comienzos del XVI, apenas hay referencias a la casa, salvo cuando el material es el yeso, lo que debía llamar la atención, como se indica en varios sitios: en Moratilla «todos los hedeficios deste lugar son de yelso», lo mismo se dice en Pastrana y en Tendilla (1, II, pp. 176-79).

Cal.-Se cita en muchas localides alcarreñas, aunque no tantas como el yeso, sin duda porque la fabricación exige en los hornos mayor temperatura y más consumo de leña. No se dice la procedencia o es del lugar, pocas veces de fuera aunque en Yélamos de Yuso (Abajo) se hace mucha «porque de él llevan a otras partes». No se indica en el mapa.

Figura, a la vez que la piedra, entre los materiales en Alhóndiga, Bujalaro, Cifuentes, El Olivar, Quer, Romancos, Sayatón, Tendilla; bastantes más, una veintena, en la forma de calicanto (generalmente solo algunas casas: Albalate, Albares, Alcocer, Almoguera, Almonacid, Alocén, Berninches, Fuentes, Horche, Irueste, Ocentejo, Peñalver, Trillo, Valdeloso, Valdeavellano, Valdesaz, Valtablado, Yélamos de Yuso; en la Campiña sólo en Azuqueca y Uceda, valle arriba en Bujalaro. En Mondéjar se cita «mampostería de cal»; en Marchamalo, Quer y Usanos, en la Campiña, y en la inmediata Taracena, algún pilar de ladrillo y cal.

Debe ser cal o una mezcla, el producto usado para enjalbegar en Quer, única mención de este tipo; allí son los cimientos de piedra y el resto tapiería, a veces con pilares de ladrillo y cal, «por gran regalo bañamos o jabelgamos las paredes por de dentro con tierra blanca» y sobre la puerta "algunas señales blancas desta tierra» $\left(3,46\right.$, resp. ${ }^{\text {a }}$ 32, p. 301).

Varios tipos.-En bastantes lugares las casas corresponden a varios de los tipos antes indicados; no sabemos si es por una mayor 
precisión en las respuestas o porque realmente son variados. Hay mucha diversidad en los detalles, pero se pueden establecer varios grupos. 1) Viviendas de piedra y otras de tapias: Atanzón, Caspueñas, Escopete, Pastrana, Valdeavellano.-2) De piedra y otras mixtas de piedra y tapias (Escariche, Valtablado) o también con pilares de yeso (Irueste), o bien de calicanto y otras de piedra y barro y postes de yeso (Valdeloso).-3) La mayoría de yeso y algunas de calicanto (Berninches, Bujalaro, Cogolludo, Fuentelaencina, Jadraque) o también de tapiería (Almoguera, Auñón, pocas en Tendilla).

\section{Madera}

En casi todos los pueblos la cita es genérica, debe referirse esencialmente al armazón de la techumbre y, en ciertos casos, a pies derechos en paredes; incluirá también, como es obvio, la empleada en techos de habitaciones, por lo menos cuando hay dos plantas, y en puertas y ventanas.

Se emplea de tres clases y diversas procedencias: la local es de roble y encina o bien de árboles ribereños, «de los valles y vegas» (Irueste) «del río y la rivera» (El Cubillo); en menos casos se utiliza pino, casi siempre de sierras lejanas, o ambas clases. La primera, más barata, se califica muchas veces de «tosca»; la otra es de mayor precio, así en Cañizar se dice que «es cara», en Quer sólo «los que más pueden labran algún aposento con maderas de pino que se trae de fuera», en Atanzón las viviendas corrientes son de «olmos e otras maderas e no de pino... algunas en particular ay de calicanto y pino», etc.

Ha de tenerse en cuenta la mayor extensión y mejor porte entonces de los montes de frondosas, que daban piezas maderables; por el contrario hay en la actualidad pinares de repoblación en lugares donde no existía ese arbolado antaño. También ha de considerarse la forma de transporte en el XVI, difícil en muchos casos mediante carretas por malos caminos, en cambio a lo largo del Tajo circulaban libremente las maderadas.

La clase y origen se indica casi siempre, en cambio pocas veces la forma de empleo o las piezas. En Fuentes la armadura de las casas «es de madera tosca... sobre pies de madera» y si es menester pino, 
viene de Trillo; en Almoguera se usa pino de Cuenca, pero en las «bajadas y obra tosca» es pino local, sauce y olmo; en El Cubillo «las maderas tiriantes e carreras gordas son de saces y olmos que ay en el lugar», pero «la ripia y cabríos» son de la sierra de Galve, la ripia es tabla delgada y tosca para asentar las tejas, también se menciona en Miralcampo (cerca de Azuqueca), Robledillo, Usanos, etc.

Maderas locales.-Son las empleadas únicamente en la mayoría de los pueblos, de diverso tipo según las comarcas, aunque en bastantes casos no se indica la especie, es madera "tosca», «del lugar», «de la tierra», etc. Así, en diversos pueblos del valle medio del Henares y la Campiña: Benalaque (despoblado al $\mathrm{N}$ de Alovera), Beleña, Bujalaro (con pino), Cogolludo, Fuencemillán, Galápagos, Jadraque (con pino), Muriel y Puebla de Beleña (fig. 4); así mismo en la Alcarria: Aldeanueva de Guadalajara, Armuña, Brihuega, (con pino), Fuentenovilla, Iriépal (con pino), Romancos, Sayatón, Viana de Mondéjar y Yélamos de Yuso (con pino).

El roble y la encina (pocas veces llamada carrasca), de los montes locales, se emplea en muchos sitios. En la Sierra del Norte aquél será Quercus Pyrenaica, de terrenos silíceos, hoy con montes muy menguados; se mencionan en Angón, Alcorlo, Arroyo de las Fraguas, Bustares, Gascueña, Hiendelaencina, Villares y Zarzuela; en Cardeñosa y Rebollosa también olmo.

En el valle medio del Henares y en la Alcarria, igualmente, encina y roble, pero éste sería $Q$. faginea, la subespecie calcícola, en las umbrías, más exigente en humedad que la encina; también árboles de los sotos ribereños, olmo sobre todo (alguna vez llamado álamo negro) y sauce (generalmente denominado «saz»), en pocos sitios álamos o chopos (alguna vez llamados «pobos»). En el Henares medio se citan en Carrascosa, Cendejas de Enmedio y de la Torre, Huérmeces, Medranda, Matillas, Negredo, La Olmeda, San Andrés del Congosto y Santiuste; en Vianilla (hoy Viana de Jadraque) es carrasco y enebro. En la Alcarria aparecen en pocos sitios dispersos: Budia (con pino), Gárgoles de Arriba, Peñalver, Valdeavellano, Yebra (con pino) y Yélamos de Yuso.

En una decena de pueblos alcarreños, con sotos en los ríos, se utilizan únicamente los árboles de ribera: Balconete, Centenera, Chiloeches, Hueva, Irueste, Lupiana, Moratilla, Pioz, Valderachas y Yebes; en la Sierra, solamente en Riofrío. En otros lugares alcarreños 


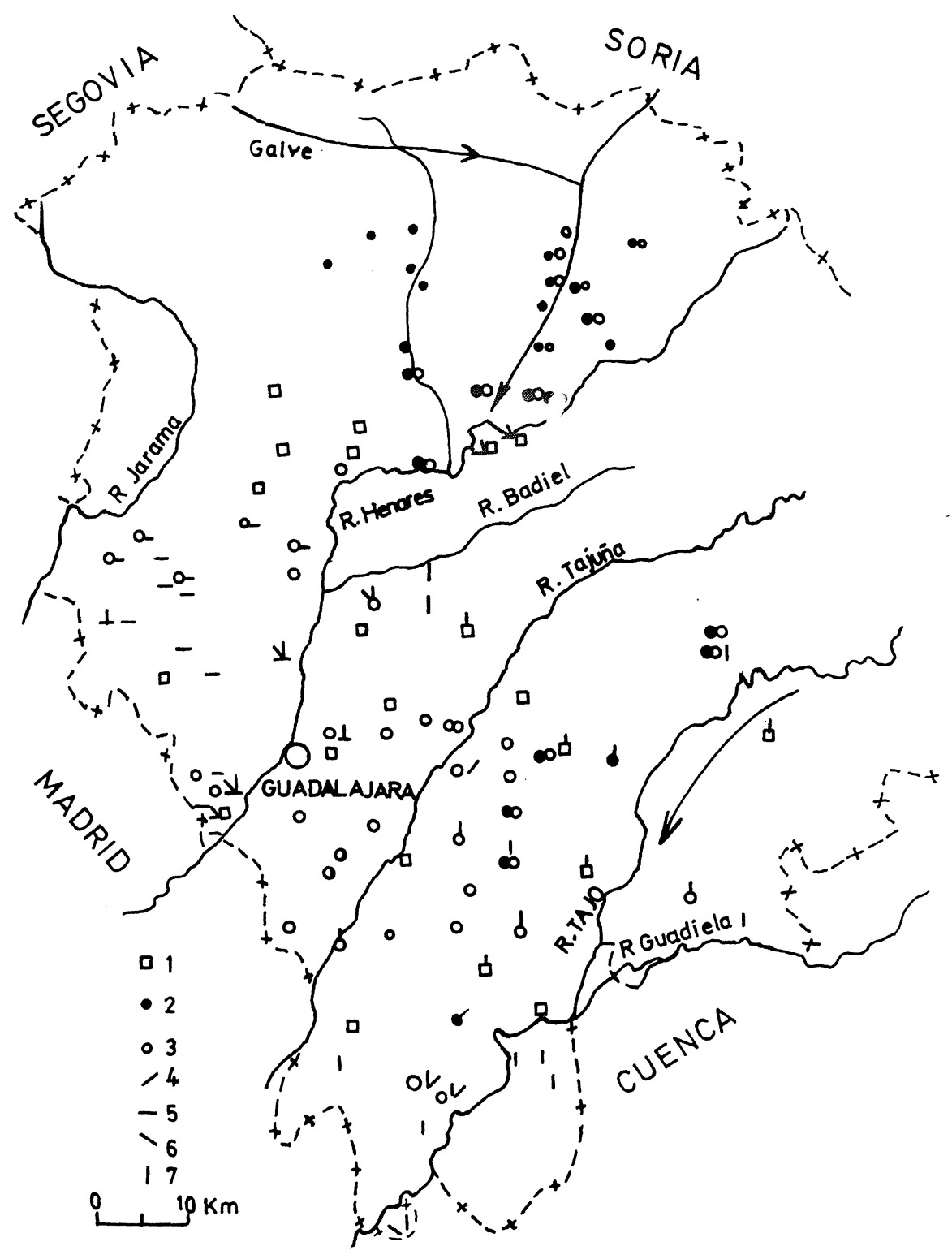

FIGURA 4.-Clase y origen de la madera. 1, local sin especificar; 2 , roble, encina; 3, árboles de ribera; 4, pino local; 5, id. de Galve; 6, id. de San Leonardo; 7, id. de Cuenca, Molina, etc. Flechas, rutas de la madera. 
también se usa pino: Almoguera, Albares, Cañizar, Horche, Loranca, Moratilla, Taracena, Tendilla. Igualmente en la Campiña: Alovera, Casa de Uceda, El Cubillo, Fuente el Fresno (despoblado en Fuentelahiguera), Quer y Robledillo de Mohernando; en Mohernando y Montarrón sólo árboles de ribera.

Pino.-Se emplea su madera en bastantes sitios de la Alcarria y la Campiña, de forma única o a la vez que las especies locales; llama la atención que no se cite en la Sierra septentrional, como luego explicamos. En general, se dice la procedencia, o se puede deducir, y ello ilustra mucho respecto al comercio por «carreterías» (no se menciona expresamente) o el transporte fluvial.

Solamente en cuatro pueblos alcarreños se utiliza pino «de la tierra» o «del lugar». En Escopete de forma única, en Valfermoso (de Tajuña) a la vez que árboles de ribera, en Albares y Almoguera también pino de Cuenca, en Yebra sin especificar.

En los demás sitios viene de los pinares de Galve (en el N de la provincia) o del Alto Tajo (esencialmente Cuenca) y de forma secundaria de San Leonardo, en Soria. Los de Galve, de Pinus sylvestris y relativamente bien conservados hoy, tienen su centro en dicha localidad, pero se extienden a las próximas; en las Relaciones se dice «pino de Galbe» o «de la sierra de Galbe», aunque este segundo nombre no se emplea hoy por incluirse en la sierra de Alto Rey. Por el viejo camino hacia Atienza saldrían las carretas (aún las hemos visto emplear en la saca de los montes) a la antigua ruta de Soria a Jadraque y el valle del Henares. Se menciona esta madera, en ocasiones a la vez que la local, en varios pueblos del valle medio (Jadraque, Bujalaro) y en la Campiña: Alovera, Fontanar, El Cubillo, Puebla de Guadalajara (despoblado al NW de Usanos), Usanos, Quer, Robledillo de Mohernando, Valdenuño Fernández y Villanueva de Guadalajara (de la Torre). En otros de la misma comarca se dice que procede de 7 a 10 leguas, por lo cual también será de Galve: Fuentelahiguera, Humanes, Villaseca de Uceda, Viñuelas y Miralcampo (en Azuqueca); todavía se cita en la inmediata Alcarria, en Taracena.

Por el citado camino de Soria también llegaría de San Leonardo en el alto Duero, a Jadraque y Bujalaro y, en la Campiña Baja, a Alovera, Benalaque y Fontanar, en la Alcarria inmediata sólo se menciona en Cañizar, todos en el camino del Henares.

La otra gran zona abastecedora de la Alcarria, es Cuenca o sierra

$$
-660-
$$


de Cuenca, también Molina en algún caso o Trillo, por los aserraderos. En muchos sitios se especifica el transporte por el Tajo, o se llama «madera del Tajo», y en algún caso por el Guadiela (Almonacid, Córcoles). En Trillo se mencionan tres edificios con «sierras de agua» y es actividad de los vecinos llevar madera de las sierras de Cuenca y de Molina a Toledo y otros sitios o «aserralla en este lugar», para la venta posterior en el Campo de Guadalajara, Alcalá y Madrid (respuesta 31 y 35, p. 362). Así se comprueba en diversas relaciones madrileñas y toledanas $(9,11)$. En la relación de Loranca se dice que por madera de pino se va a la ribera del Tajo, «con la panxia donde la hay y se labró la dicha madera» (XLV, p. 193). Pangía figura en el mapa de Tomás López junto al Tajo, al S de Pastrana, no la cita Madoz; en la Cosmografía de España de Fernando Colón, en el camino de Pastrana a Zorita, en un arroyo, «ay dos sierras de agua que hazen madera, la una en la boca del arroyo como entra en Taxo e la otra media legua más arriba» (1, II, p. 175).

Se indica como madera única en Albalate, Alcocer, Almonacid, Mazuecos, Mondéjar, Trillo y Valdeloso (despoblado al N de Alcocer); en otros pueblos a la vez que la local: Almoguera, Albares, Auñón, Budia, Cañizar, Córcoles, Fuentes, Fuentelaencina, Gárgoles de Abajo, Horche, Loranca, Pastrana, Taracena, Tendilla, Valdeconcha, Viana de Mondéjar, Yélamos de Arriba; también Ciruelos, donde el «ripión» es de acarreo.

El límite occidental de esta madera se halla en el bajo Henares, donde coincide con la de Galve; al E del río se citan ambas en Taracena, al W, ya en la Campiña, en Fontanar y Benalaque (allí también de San Leonardo), como ya se indicó; debe ser un error la mención de Mesones, mucho más lejos.

En cambio el límite hacia el $\mathrm{N}$ de la Alcarria queda indeciso. En Fuentes y Cañizar aún se dice que viene de Trillo (en el segundo lugar también de San Leonardo); en Taragudo, Valdearenas y Trijueque no se cita origen, probablemente aún es de Cuenca; más allá, en Jadraque y Bujalaro, en el Henares, es ya de Galve y San Leonardo.

No hay relaciones de la zona pinariega de Galve ni de los valles del entorno de Atienza, en ésta y por lo menos en las casas grandes de los pueblos, se utilizaría pino. Por el contrario, llama la atención que no se mencione, a pesar de la relativa proximidad, en los pueblos serranos de que hay relaciones, sobre todo los del NE, en el valle del

$$
-661-
$$


Salado, precisamente en la ruta de las carreterías. Una razón general debe ser la mejor calidad, entonces, de los montes locales de roble y encina, y en algunos también los sotos, unido a la pobreza de los pueblos; rasgo este último muy acusado en el áspero macizo paleozoico del NW (5), en el cual, además, no había caminos carreteros debido al obstáculo de la sierra de Alto Rey y los encajados cursos de los ríos; el primero de aquéllos es de la segunda mitad del XIX, desde Hiendelaencina, debido a las minas de plata, hacia el Heneres.

\section{Cubierta}

Excepto en las sierras del macizo antiguo septentrional, debía ser común la teja que se cita en una treintena de sitios, de los cuales una docena pertenecen a la Campiña y el resto a la Alcarria ${ }^{3}$. En unos casos se incluye simplemente entre los materiales empleados, en otros se especifica que así es la cubierta. En la mayoría no se indica el origen, en seis se hace en el pueblo y en diez se trae de fuera; en uno de aquéllos, en El Cubillo (en la Campiña), donde se hace mucha, es «cocida con paja de rastrojos, zarzas y escobas». En algunos pueblos se cita la «ripia» o tablillas sobre la que se colocaría; la disposición general sólo se menciona en Alhóndiga: la mayor parte «tienen los tejados a un agua», y en Balconete se especifica que son «tejas canales» (¿sólo las vueltas hacia arriba?) ${ }^{4}$.

La paja, empleada en algunos pueblos de los alrededores de Madrid, varios de Ciudad Real y, sobre todo, en la Sagra toledana (9, 10, 11), sólo aparece en dos de la Campiña, en Fresno de Málaga (despoblado en Málaga del Fresno) «algunas con covertura de paja y otras techadas» y en Villanueva de Guadalajara (hoy de la Torre), «cubiertas de sus texados y algunas cubiertas con paja» (fig. 5).

\footnotetext{
3 En La Campiña: Cabanillas, Casa de Uceda, El Cubillo, Fuente del Fresno, Galápagos, Miralcampo, Mesones, Mohernando, Puebla de Guadalajara, Quer, Usanos, Villaseca de Uceda. En La Alcarria: Aranzueque, Archilla, Auñón, Benalaque, Ciruelas, Fuentenovilla, Fuentes, Retuerta, Romancos, Taragudo, Trijueque, Valdesaz, Valtablado, Yebes y Zorita de los Canes.

4 Todavía hoy se ven así en casas modestas, especialmente en la Sierra Norte (5). Según el Diccionario de la Academia, «teja canal» es la delgada y más combada que las comunes, la cual sirve en los tejados para formar los conductos por donde corre el agua (ed. 1970, p. 240).
} 


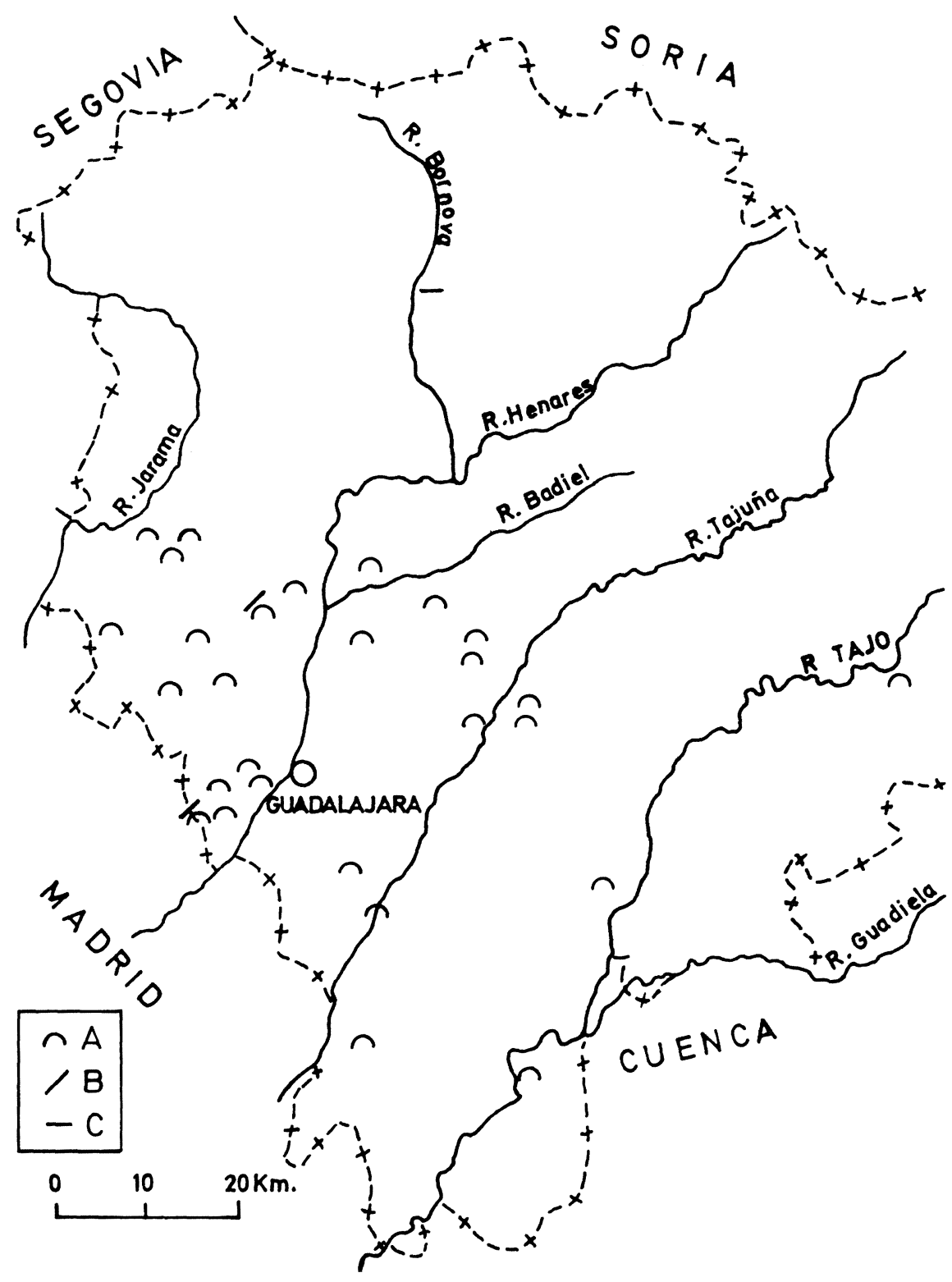

Figura 5.-Cubierta. A, teja; B, paja; C, piedra. 
Salvo un lugar, no se indica la techumbre en las sierras septentrionales. En el macizo antiguo sería de pizarra o neis, como todavía hoy en muchos lugares (5), posiblemente también ramas y paja, como en los Montes de Toledo (11); solamente en Hiendelaencina, en el centro del macizo, se dice «pizarra para tejados» (3, XLV, p. 354), aunque allí no es exactamente pizarra, sino delgadas lajas de neis, como aún se ve en muchas casas de la parte vieja. En la periferia mesozoica se emplearía teja (como hoy), quizás también ramas y paja, que aún se ven en majadas (5).

\section{Conclusiones}

Son muy numerosas las relaciones de la Alcarria y hay bastantes de las tierras del Henares, pero muy pocas de las sierras del norte y ninguna del extenso resto de la provincia.

No hay datos sobre el plano y las referencias al alzado, se distribuyen por igual entre casas de una sola planta y de dos o tres, ninguna de éstas en la Campiña, salvo un lugar, ni en la Sierra.

Se utiliza solamente piedra y barro en la Sierra y en bastantes sitios de la Alcarria, allí también yeso y cal. La tapiería de tierra como material único es genuina de la Campiña. Piedra en los cimientos y encima tapiería en bastantes pueblos de la Alcarria. Se emplea poco el adobe, esencialmente, en el valle medio del Henares. Es de uso muy reducido el ladrillo, en forma de postes, en pueblos de la Campiña y alguno alcarreño.

Abunda mucho el yeso, en la mayoría de los casos se cita simplemente entre los materiales; en otros como mortero en pilares de piedra o ladrillo, o como postes de yeso o bien con la tapiería. En ciertos lugares es material casi único. Sólo en dos se emplea para revoco o enlucido. Es frecuente el uso de la cal como mortero, sólo una vez para enjalbegado.

La madera es, generalmente, de procedencia local, roble o encima de los montes o árboles de ribera (olmo, sauce, pocas veces chopo). En menos localidades se emplea pino; en la Alcarria especialmente el de Cuenca, en las tierras del Henares el de Galve (en la sierra del norte) y aun el de San Leonardo (Soria).

La cubierta era de teja, salvo en el macizo antiguo septentrional, de pizarra o neis; la de paja sólo se menciona en dos sitios de la Campiña.

$$
-664-
$$




\section{BIBLIOGRAFÍA}

1. Colón, Fernando (1988): «Descripción y Cosmografía de España», Bol. R. Soc. Geogr., 1904-6, XLVI-XLVIII; ed. parte, Madrid, R. Soc., Geogr., 1908-15, 3 vols. ed. fac. con prólogo de J. L. Mora, Sevilla, Padilla, 1988, 3 vols.

2. Flores, Carlos (1974): Arquitectura popular española, Madrid, Aguilar, t. III, 857 pp.

3. GARCía LóPez, Juan Catalina y PÉrez Villamil, Manuel (1903-15): «Relaciones topográficas de pueblos... de la provincia de Guadalajara». Memorial Histórico Español, XLI-XLIII y XLV-XLVII.

4. Garcia Mercadal, Fernando (1930): La casa popular en España, Bilbao, 93 pp., 70 láms.

5. LÓPEZ GÓmez, Antonio (1966): «La casa rural y los pueblos en la Serranía de Atienza», Est. Geográficos, n. 104, pp. 349-421.

6. - (1993): «Las comarcas de Gudalajara según las Relaciones Topográficas de Felipe II», pp. 291-308 en Homenaje académico a D. Emilio García Gómez, Madrid, R. Academia de la Historia.

7. LOPEZ GÓmez, Julia y LÓPEZ GOMez, Antonio (1989): «Fermín Caballero y las Relaciones Topográficas de Felipe II: En estudio pionero», Arbor, n. 526, pp. 33-49.

8. - (1990): «Cien años de estudios de las Relaciones Topográficas de Felipe II después de Caballero», n. 538, pp. 33-72.

9. - (1989): «La vivienda rural madrileña según las Relaciones Topográficas de Felipe II», Est. Geogr., n. 197, pp. 573-98.

10. - (1990): «La vivienda rural en Ciudad Real según las Relaciones Topográficas de Felipe II», Est. Geogr., n. 199-200, pp. 219-40.

11. - (1992): «La casa toledana en el siglo Xvi según las Relaciones Topográficas de Felipe II», Bol. R. Acad. Historia (en prensa).

12. Lopez Gómez, Julia; López Gómez, Antonio y Arroyo Ilera, Fernando (1992): «La vivienda en Cuenca en el siglo xvI, según las Relaciones Topográficas de Felipe II». El medio rural español. Homenaje al prof. D. Angel Cabo Alonso, pp. 389-401, Salamanca, Universidad.

13. SIlva; J. Gentil da (1975): «Desarrollo económico, decadencia y subsistencia en España», Madrid, Ciencia Nueva, 186 pp. (1. ${ }^{a}$ ed. francesa, 1965).

14. TORRES BALBAS, Leopoldo (1933): «La vivienda popular en España», en F. Carreras y Candi, dir.: Folklore y costumbres de España, Barcelona, A. Martín, t. III, pp. 137502. 